\title{
The Integration of ASRC System within BIM
}

\author{
Roshana Takim, Muhammad Hanafi Zulkifli, \\ Abdul Hadi Nawawi \\ Centre for Postgraduate Studies, Faculty of Architecture, Planning and Surveying \\ Universiti Teknologi Mara, Shah Alam, Selangor. Malaysia \\ dr_roshana@salam.edu.my
}

\begin{abstract}
Technically, safety planning and project execution planning has been carried out separately for most BIM-based projects. As such, it leads to difficulties in monitor these planning simultaneously during construction phase. In this regards, the Automated Safety Rule Checking (ASRC) system is perceived to distinguish fall hazards by integrating the system in the existing BIM-model. This paper pursues to explore the integration of ASRC system within BIM-based projects in Malaysia. A cross-sectional survey was employed to large public and private organisations that involved with BIM. The data were analysed by using content analysis technique and revealed that ASRC system is yet to be incorporated into BIMbased projects in Malaysia.
\end{abstract}

Keywords: ASRC System; BIM; Fall Hazard; Safety

eISSN 2398-4279 @ 2018. The Authors. Published for AMER ABRA cE-Bs by e-International Publishing House, Ltd., UK. This is an open access article under the CC BY-NC-ND license (http://creativecommons.org/licenses/bync-nd/4.0/). Peer-review under responsibility of AMER (Association of Malaysian Environment-Behaviour Researchers), ABRA (Association of Behavioural Researchers on Asians) and CE-Bs (Centre for EnvironmentBehaviour Studies), Faculty of Architecture, Planning \& Surveying, Universiti Teknologi MARA, Malaysia.

DOI: https://doi.org/10.21834/ajqol.v3i10.113 


\subsection{Introduction}

Safety is one of the most decisive aspects in the project development process. It is indeed the construction workers are threatened by various kinds of dangers (especially fall hazard) in their work environment. It has been proven by Bratcher et al. (2010) and U.S Department of Labour (2014), fall hazard in construction is contributing to most of the fatal injuries. For instance, in 2013, almost $36.9 \%$ (294 out of 796) of the construction workers died because of falls in United States (US). The probable reason could be due to lack of safety planning and safety protection equipped during the construction phase.

With the technological advancement in the construction industry (i.e., Building Information Modelling), safety hazard shall be diminished as the project progresses. This medium shall integrate both Building Information Modelling and safety planning across the project phases. According to Melzner et al. (2012), the integration may detect three (3) essential elements, including: (1) what forms of safety protections need to be installed (i.e., cover and guardrail); (2) where to install (i.e., slab edge, slab hole, and wall opening); and (3) when to plan and install the protections (i.e., design development, construction documentation and construction phase).

In relation to the above, much attention in the Architectural, Engineering and Construction (AEC) industry today is focusing on BIM for the fact that it attempts to bring many benefits including safety to the construction projects (Takim et al., 2013). Smith (2007) and Zakaria et al. (2013) states that BIM is a revolutionary technology that envisages the virtual construction progress to mitigate uncertainty, assure the adequate safety, and analyse the potential impacts as the project progresses. Hence, it is an opportunity to make full use of the benefits derived from BIM that potentially integrates both safety and health practices within BIM-based projects in Malaysia.

Alternatively, the Automated Safety Rule Checking (ASRC) system shall be used to facilitate the safety planning while the BIM-based projects are in progress. The paper seeks to explore the integration of the ASRC system within BIM-based projects in Malaysia. Correspondingly, it perceives on the understanding of the respondents on the ASRC system.

\subsection{Literature Review}

Construction is one of the industries that contribute to major rate of accidents and fatalities. The reason could be due to its nature of the environment (i.e., most dangerous and hazardous workplace) which can easily affect the worker's physical and health condition (Melzner et al., 2012; Mohammed \& Ishak, 2013). According to Abdullah \& Wern (2011), as recorded by Social Security Organization (SOCSO), the accident and fatality rates in Malaysian construction industry are increasing in a decade. This incident alarms the industry and the government about the critical scenario faced by the construction sector.

Figure 1 shows the accident and fatality rates in Malaysian construction industry reported by the Department of Occupational Safety and Health (DOSH). The statistics for the last five (5) years indicated a high number of fatalities and accidents in the construction sector. Based on the research by Mohammed \& Ishak, (2013), most of the fatality and accident rates are 
dominated by falls accident. These indicated that the fall hazard in construction remains as a serious problem faced by the industry and need to be mitigated.

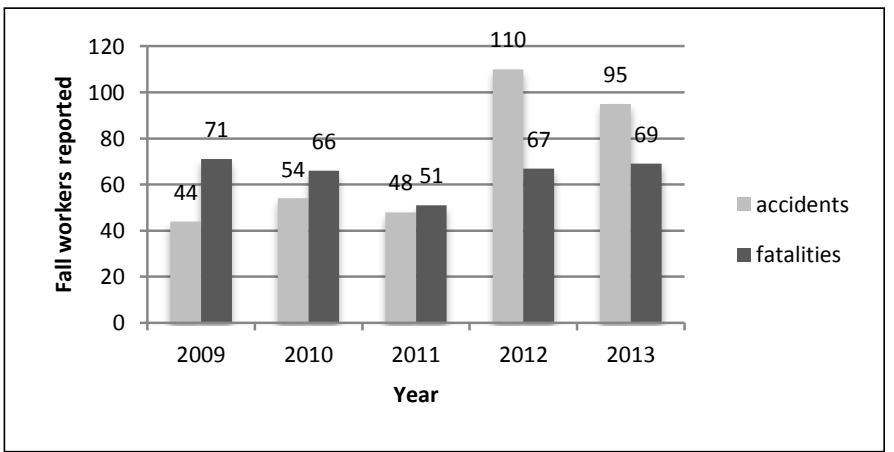

Figure 1: Reported Accident and Fatalities in Malaysia Construction Industry for 2009-2013 (Source: DOSH, 2014)

There are two folds of national agendas related to fatalities and accidents in construction including; (1) strategic thrust 1 in Construction Industry Transformation Programme (CITP) which is to strive for the highest standard of quality, safety and professionalism ingrained in industry culture; and (2) objective in occupational safety and health (OSH) Master Plan 15 which is to reduce the rates of workplace injuries and associated fatalities. For this matter, the accident and fatality rates need to be reduced by all means in order to achieve minimum rates of injuries in the construction project. The growing implementation of BIM in the AEC industry is changing the way of safety in construction across project phases (Zhang et al., 2013). This medium shall be addressed by deploying and integrating the ASRC system in a BIM-based project.

According to Zhang et al., (2013), there are three (3) possible problems in current state of safety planning; (1) still relies on frequent manual observation in which the link between safety planning and construction planning is often too weak and highly inefficient (i.e., depending on 2D drawings); (2) difficulty in transferring the safety knowledge (i.e., different safety culture for different project); and (3) full responsibility of site safety which typically handled by project contractors. As a result, it will inadvertently produce the hazards during planning and project execution phase. Thus, ASRC system shall mitigate these problems by automatically detect on what, where, and when the safety protection need to be deployed (Melzner et al. 2012).

Nonetheless, in order to integrate the system in Malaysia's BIM-based project, the guidelines formed by the Department of Occupational Safety \& Health Malaysia (DOSH) need to be perceived. Literally, three (3) standard of guidelines related to fall hazards were outlined by DOSH (2007). The first guideline is regarding holes and pit on floor areas. According to the specifications, all holes or penetrations on the slab or working areas shall be covered with the secured cover (i.e., light-duty platform cover). Conversely, if the covers 
are impractical, guardrails or barriers shall be erected. The second guideline considered in ASRC system is wall openings. The guideline written by DOSH (2007) stated that any exposed openings (i.e., doors, windows, or other services) that possibly lead to fall more than 2 metres shall be protected with guardrails. This is in-line with Occupational Health and Safety (OSHA)-US stated that the safety protection system (i.e., guardrail system, safety net system or a personal fall arrest system) shall be erected if the outside bottom edge of the wall opening is greater than $1.8 \mathrm{~m}$ from lower levels, and the inside bottom edge of the wall opening is less than $1.0 \mathrm{~m}$ above the working surface (OSHA, 2012). The third guideline that needs to be considered is the precaution of the floor and work platform perimeter edges. According to Malaysia and US guidelines (DOSH, 2007; OSHA, 2012), guardrails are required if the exposed edge of floors that possibly lead to 1.8 metres fall, while toe board is necessary if the objects can fall from the edge. Besides, the other means of protection (i.e., safety net system, of personal fall arrest system) shall be equipped when the guardrails are impractical.

\subsection{Methodology}

Figure 2 proposes an initial framework of ASRC system within BIM-based projects in Malaysia. The framework consists of safety guidelines (based on US, German and DOSH Malaysia) to be integrated within BIM-based project Model. In order to develop the framework further, the first step is to gather and analyse the fall hazard guidelines from various countries (i.e., German, US and Malaysia). Three (3) fall hazard guidelines are recognised which includes: (1) slab holes protections, (2) slab edges protections and (3) wall opening protections. These guidelines shall be integrated within the BIM-based model as developed by the designers and engineers at project planning stage. The purpose is to adhere to the current Malaysian National agenda through Construction Industry Master Plan (CIMP 2) and OSH Master Plan 15. This is also in-line with the ideas of Zhang et al. (2013) and Melzner et al. (2012), stating that the existing guidelines and best practices shall be applied either within BIM tools (i.e., Revit, Archicad, and Tekla) or BIM platform (i.e., Naviswork and IFC platform). Nevertheless, to date, it is difficult to perceive ASRC system in Malaysia's BIMbased project for the fact that the implementation of safety is yet to be incorporated within the implemented BIM-based projects.

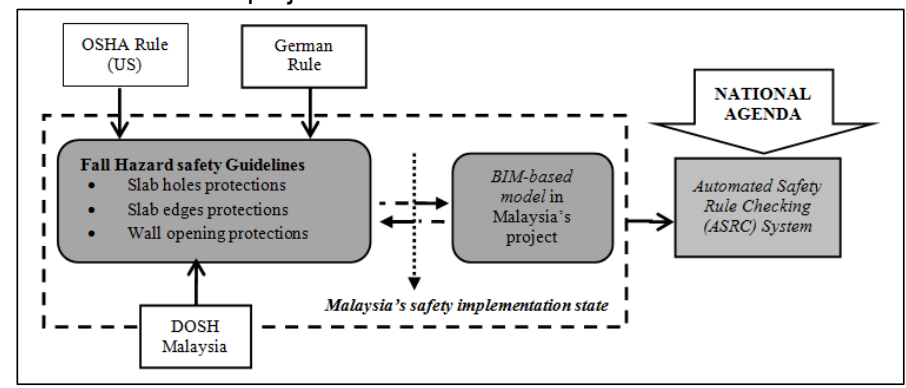

Figure 2: Initial Conceptual Framework of ASRC System within BIM-based Projects in Malaysia 
In this regard, this study commences with the spearhead of literature collection of ASRC system in BIM-based projects based on the experiences from the German and US as shown (see Table 1). The study shows the installation of ASRC system for 'holes in slab'. According to Melzner et al. (2012), US and German already develop their rules to install the safety protection system (i.e., light-duty platform cover and guardrail system). OSHA (US) rule stated that if the hole is within $0.05 \mathrm{~m}$ and $1 \mathrm{~m}$, a cover should be applied. Otherwise, if the holes are larger than $1.00 \mathrm{~m}$, guardrails are practicable. On the other hand, German rule stated that cover should be applied if the holes are less than $3.00 \mathrm{~m}$ and guardrail system are applicable if the holes are larger than $3.00 \mathrm{~m}$.

Table 1: Installation of Safety Protection System (Hole in Slab)

\begin{tabular}{llll}
\hline OSHA rule (US) & & German rule & \\
\hline Length of hole & Action & Length of hole & Action \\
\hline$<0.05 \mathrm{~m}$ & No action required & $<3.00 \mathrm{~m}$ & Apply cover \\
$0.05 \mathrm{~m}<\mathrm{x}<1.00 \mathrm{~m}$ & Apply cover & & Apply guiderail system \\
$>1.00 \mathrm{~m}$ & Apply guardrail system & $>3.00 \mathrm{~m}$ &
\end{tabular}

(Source: Melzner et al., 2012)

Based on the guidelines from the US, German and DOSH Malaysia, the data collection focuses on the integration of the ASRC system within the BIM-based project in Malaysia. Samples are collected from both public and private organisations which have involved and endured in BIM-based construction project(s). A face-to-face semi-structured interview (cross-sectional study) has been conducted to these organisations. The interview was conducted on November 17-19, 2014 to four (4) respondents (i.e., 3 respondents from public and 1 from private organisations). The purpose is to explore the integration of ASRC system within BIM-based projects in Malaysia. Four respondents were targeted because they are conversant in BIM within BIM-based projects. Four (4) significant questions were asked which includes: definitions of ASRC system; incorporation of ASRC system with BIM-based project(s) (what to apply); the recommended phases to apply ASRC system (when to apply); and the application of ASRC system in recommended project phase(s) (where to apply). The data were analysed and synthesised by means of content analysis techniques.

Table 2 shows the respondent's information to the involvement of BIM-based projects in Malaysia. Seventy-five percent $(75 \%)$ of them have more than 10 years working experience in the construction industry and also have an average of 5 years involvement in BIM-based projects (since BIM was founded in Malaysia- year 2007).

Table 2: Respondent's Information

\begin{tabular}{lllll}
\hline \multirow{2}{*}{ Respondents } & Type of Organizations & Designation & \multicolumn{2}{l}{ Years of Experience } \\
\cline { 4 - 5 } & & Industry & $\begin{array}{l}\text { BIM-based } \\
\text { projects }\end{array}$ \\
\hline Respondent 1 & Public organization & Chief Assistant Manager (Architect) & 16 years & 7 years \\
Respondent 2 & Public organization & Assistant Manager (Architect) & 10 years & 4 years \\
Respondent 3 & Public organization & Assistant Manager (Architect) & 9 years & 4 years \\
Respondent 4 & Private organization & Design Executive & 20 years & 5 years \\
\hline
\end{tabular}


From the table, it shows that the respondents are knowledgeable in BIM and may support the initial findings.

\section{Integration of ASRC System in Malaysia}

Table 3 presents the outcomes of the interview. Based on the results, three (3) of the respondents $(75 \%)$ from both sectors (public and private) agreed that ASRC system is defined as an integrated system for construction and safety management based on 4D model technique. Furthermore, $50 \%$ of the respondents seconded the definition by Sulankivi et al. (2010) stating that it is an integrated safety rule checking system based on 4D model developed in planning stage to assist safety checking system in the construction phase. These definitions implied that ASRC system is an integrated safety rule checking system to be incorporated at project planning stage. The purpose is to assist project team members in the later construction project phases in dealing with safety protection measures by using a 4D-BIM model technique.

Table 3: Results of survey - Automated Safety Rule Checking System (ASRC) across project phases in Malaysia

\begin{tabular}{|c|c|c|c|c|c|c|}
\hline \multirow[b]{2}{*}{ Res } & \multirow{2}{*}{$\begin{array}{l}\text { Definition of ASRC } \\
\text { system }\end{array}$} & \multirow{2}{*}{$\begin{array}{l}\text { Incorporation with ASRC } \\
\text { system }\end{array}$} & \multicolumn{3}{|c|}{$\begin{array}{l}\text { Suggested phase(s) to apply } \\
\text { the ASRC system }\end{array}$} & \multirow[b]{2}{*}{ Application of ASRC system } \\
\hline & & & $\begin{array}{l}\text { Design } \\
\text { phase }\end{array}$ & $\begin{array}{l}\text { Proc. } \\
\text { phase }\end{array}$ & $\begin{array}{l}\text { Const. } \\
\text { phase }\end{array}$ & \\
\hline \multirow[t]{2}{*}{ R1 } & $\begin{array}{l}\text { An integrated safety rule } \\
\text { checking system developed } \\
\text { in planning stage to assist } \\
\text { project team for } \\
\text { construction phase }\end{array}$ & $\begin{array}{l}\text { "BIM is not reaching that level } \\
\text { yet" } \\
\text { "the implementation of ASRC } \\
\text { system at construction phase } \\
\text { may allow to focus on safety } \\
\text { task" }\end{array}$ & & & $\sqrt{ }$ & $\begin{array}{l}\text { Focus the task when the } \\
\text { construction begins with the } \\
\text { involvement of safety officer }\end{array}$ \\
\hline & & $\begin{array}{l}\text { No -Lack of knowledge and } \\
\text { awareness in safety culture \& } \\
\text { safety is less to contemplate }\end{array}$ & & & & \\
\hline \multirow[t]{2}{*}{ R 2} & $\begin{array}{l}\text { An integrated system for } \\
\text { construction and safety rule } \\
\text { checking system based on }\end{array}$ & $\begin{array}{l}\text { "ASRC system in design phase } \\
\text { may improve the project } \\
\text { delivery by reducing the cost" }\end{array}$ & $\sqrt{ }$ & & & $\begin{array}{l}\text { By integrating safety } \\
\text { protections - with 3D } \\
\text { Modelling }\end{array}$ \\
\hline & & $\begin{array}{l}\text { No-Costly for software design } \\
\text { and lack of expertise }\end{array}$ & & & $\sqrt{ }$ & $\begin{array}{l}\text { The supervision by the parties } \\
\text { on site }\end{array}$ \\
\hline \multirow[t]{2}{*}{ R 3} & $\begin{array}{l}\text { An integrated system for } \\
\text { construction and safety rule } \\
\text { checking based on } 4 \mathrm{D} \\
\text { model }\end{array}$ & $\begin{array}{l}\text { "at procurement phase, the } \\
\text { safety protection elements shall } \\
\text { be inserted" }\end{array}$ & & $\sqrt{ }$ & & $\begin{array}{l}\text { Insert the safety rules checking } \\
\text { elements in the tender/contract }\end{array}$ \\
\hline & $\begin{array}{l}\text { A software that does not } \\
\text { modify a building design, } \\
\text { but evaluates it on the basis } \\
\text { of configured building } \\
\text { objects }\end{array}$ & $\begin{array}{l}\text { No-Lack of expertise-a tedious } \\
\text { job in billing items }\end{array}$ & & & $\sqrt{ }$ & $\begin{array}{l}\text { Main contractor have to abide } \\
\text { on the agreed contract - safety } \\
\text { rule checking elements at } \\
\text { construction phase }\end{array}$ \\
\hline \multirow[t]{2}{*}{ R 4} & $\begin{array}{l}\text { An integrated system for } \\
\text { construction and safety rule } \\
\text { checking based on 4D-BIM } \\
\text { model }\end{array}$ & $\begin{array}{l}\text { "the safety elements shall be } \\
\text { identified to cvoid double } \\
\text { handling" }\end{array}$ & $\sqrt{ }$ & & & $\begin{array}{l}\text { The integration of safety rule } \\
\text { checking and 3D-model at } \\
\text { planning stage for further } \\
\text { inspection }\end{array}$ \\
\hline & $\begin{array}{l}\text { An integrated system } \\
\text { developed in planning stage } \\
\text { to assist safety checking } \\
\text { system in construction } \\
\text { project phase }\end{array}$ & $\begin{array}{l}\text { No- Failed to incorporate safety } \\
\text { in the software design, } \\
\text { contemplate on other issues } \\
\text { such as interoperability and } \\
\text { clash detection }\end{array}$ & & & & \\
\hline
\end{tabular}

Besides, unanimously, $100 \%$ of the respondents agreed that the ASRC system is yet to be incorporated into the BIM-based projects in Malaysia ever since 2007. This proclamation 
is supported by the statement of Respondent 1 stating "our BIM is still not reaching that level yet. We still use the conventional method to identify the safety protections in construction". The reasons could be due to lack of knowledge and awareness on the importance of safety issues in the BIM-based project. Nevertheless, they realised the usefulness of integrating ASRC system for design, procurement and construction phases.

Meanwhile, Respondent 2 and 4 suggested that ASRC system should be applied during project design phase. It is vital for the fact that the integration may ease the planning for both safety and project execution planning. Respondent 4 claimed that "when the ASRC system has been executed during design stage, the safety elements shall be identified to avoid double handling work - to design the building model and later redesign the building model incorporating safety rule checking system at the construction phase." This statement is inline with the statement made by Palumbo (2010) indicating that the safety planning during the design phase is more efficient than to plan during the construction phase. In addition, respondent 2 emphasised that "the ASRC system in design phase may improve the project delivery by reducing the cost (i.e., by early prediction of the expense of the suitable safety protection) reduce the construction time (i.e., by early planning on when and what safety protection needed), and increase the project quality (i.e., by putting the safety in the first place)".

In addition, 25\% (1 out of 4) of them suggested that ASRC system shall be applied at project's procurement phase. The respondent 3 highlighted that "at the procurement phase, the safety protection elements shall be inserted in the contract for the contractors to price it together with the model". This assertion is similar to Melzner et al. (2012) stating that a 3Dmodel safety protections could be incorporated in the bill of quantity and to be applied on every single item. Consequently, safety rule elements shall be included in the contract (i.e., numbers and cost) and the contractor should abide by the agreed contract.

The construction phase is the most important phase to apply the ASRC system. Seventy-five percent $(75 \%)$ of the respondents advocated that the ASRC system should be implemented in this phase. Respondent 1 highlighted "the implementation of ASRC system at the construction phase may allow the construction parties to focus on safety tasks by the involvement of safety officer instead been handled solely by the project architect." This statement corroborates with the idea of Gambatese \& Hinze (1999) indicating that owners play the important role in monitoring the construction safety at construction phase to maintain the quality of the project to allow contractors delivering project safely. This is also in-line with the Respondent 2 stating that "all of the construction parties (i.e., owner, consultant and contractor) are required to supervise and monitor the project together to deliver the project safely by using a 3D-BIM Model".

Hence, despite the ASRC system is significant and could be applicable across project phases in Malaysia, the implementation is yet to be realised. Among others, this could be due to ASRC system is costly to be incorporated in the software design, and failed to contemplate on safety matters compared to other issues such as clash detection and interoperability in BIM-based projects. The discussion above concludes that ASRC system is vital across project phases of BIM development process by integrating safety rule checking system within the 3D-model of BIM-based construction projects. 


\subsection{Conclusion}

This research identified the integration of Automated Safety Rule Checking (ASRC) system for a safety planning BIM-based project in Malaysia. Unfortunately, the ASRC system is yet to be incorporated in Malaysian BIM-based construction projects by public and private construction organisations despite they comprehend the significant of this system. Six (6) possible reasons were gathered including: lack of knowledge in safety culture; lack of safety awareness; higher cost for software design; lack of expertise; failed to incorporate safety into the software design and contemplating on other issues (i.e., clash detection and interoperability) in BIM.

Nevertheless, the integration of the ASRC system within BIM-based project could be realised through the project development process across project phases (i.e., design, procurement and construction). At the design phase, the integration of safety rule-checking and 3D-BIM model could mitigate the planning for both safety and project execution planning. The costs of safety protection items will be inserted and price in the tender document at the procurement phase together with the 3D-BIM Model. The ASRC system will be implemented at project construction phase through a supervision of safety officer to deliver the project safely by using a complete 4D-BIM Model.

The integration of ASRC system could bring three (3) significant advantages; (1) to eliminate hazards as the project progresses, (2) to combine safety regulations and best practices in the BIM-based project, and (3) could enhance safety checking rule system across project phases. Hence, it is inevitable for the BIM-based project in Malaysia to incorporate the new ASRC system to enhance the safety planning management as a whole in the AEC industry leading to a good quality of life. Further research is to investigate various models of safety rules checking algorithms within BIM-based projects across the globe (i.e., Finland, US, Thailand and China) and to document various components of safety rule checking algorithms. The results will be reported in the next paper.

\section{References}

Abdullah, D. N. M. A., \& Wern, G. C. M. (2011). An Analysis of Accidents Statistics in Malaysian Construction Sector. In 2010 International Conference on E--business, Management and Economics (Vol. 3, pp. 1-4). Hong Kong: IACSIT Press.

Bratcher, B., Ruttenberg, R., \& Obando, M. (2010). CPWR Technical Report: Analysis of Work-Related Safety \& Health Hazards of Unrepresented Workers in the Iron Working Industry. The Centre for Construction Research and Training. Retrieved from http://www.elcosh.org/record/document/2055/d001031.pdf

DOSH. (2007). Guidelines For the Prevention of FALLS at Workplaces. Putrajaya, Malaysia.

DOSH (2014). Occupational Accident Statistics by Sector until March 2014. Available at http://www.dosh.gov.my/index.php?option=com_content\&view=article\&id=1789\&ltemid=545\&lang=en

Gambatese, J., \& Hinze, J. (1999). Addressing construction worker safety in the design phase. Automation in Construction, 8, 643-649. 
Melzner, J., Zhang, S., Teizer, J., Hollermann, S., \& Bargstädt, H. (2012). Safety planning based on an objectoriented building model. In Proceedings of the EG-ICE Conference 2012. Munich, Germany.

Mohammed, Y. D., \& Ishak, M. B. (2013). A Study of Fatal and Non-Fatal Accident in Construction Industry. Malaysian Journal of Civil Engineering, 25(1), 106-118. Retrieved from http://civil.utm.my/mjce/files/2014/04/Paper10-251.pdf

OSHA. (2012). Occupational Safety and Health.Standards Guarding floor and wall openings and holes. Retrieved May 11, 2015, from https://www.osha.gov/pls/oshaweb/owadisp.show_document?p_table=STANDARDS\&p_id=10757

Palumbo, A. (2010). Safety in design: Enhancing Construction Safety by Implementing Safety in the Design Phase. CM eJournal, 1-32.

Smith, D. (2007). An Introduction to Building Information Modeling (BIM). Journal of Building Information Modeling, 12-14. Retrieved from https://www.wbdg.org/pdfs/jbim_fall07.pdf

Sulankivi, K., Zhang, S., Teizer, J., Charles, M., Kiviniemi, M., Romo, I., \& Granholm, L. (2010). Utilisation of BIMbased Automated Safety Checking in Construction Planning. In CIB World Congress.

Takim, R., Harris, M., \& Nawawi, A. H. (2013). Building Information Modeling (BIM): A New Paradigm for Quality of Life Within Architectural, Engineering and Construction (AEC) Industry. In Procedia - Social and Behavioral Sciences (Vol. 101, pp. 23-32).

U.S Department of Labour. (2014). Commonly Used Statistics. U.S. Department of Labor. Retrieved from https://www.osha.gov/oshstats/commonstats.html

Zakaria, Z. Bin, Bin Zakaria, Z., Mohamed Ali, N., Tarmizi Haron, A., Marshall-Ponting, A. J., \& Abd Hamid, Z. (2013). Exploring the adoption of Building Information Modelling (BIM) in the Malaysian construction industry: A qualitative approach. International Journal of Research in Engineering and Technology, 2, 384-395. Retrieved from http://usir.salford.ac.uk/30827/

Zhang, S., Teizer, J., Lee, J.-K., Eastman, C. M., \& Venugopal, M. (2013). Building Information Modeling (BIM) and Safety: Automatic Safety Checking of Construction Models and Schedules. Automation in Construction, 29, 183195 